\section{Algunos clásicos de la ilustración para niños en Latinoamérica}

\author{
SERGIO ANDRICAÍN \\ Revista Cuatro Gatos
}

\author{
Sergio Andricaín \\ Sergio Andricaín (La Habana, Cu- \\ ba, 1956) es un escritor, crítico, \\ investigador literario y editor. Au- \\ tor de obras para niños como $\mathrm{La}$ \\ vuelta al mundo en cinco cuentos, \\ Libro secreto de los duendes, $\mathrm{Ha}$ - \\ ce muchísimo tiempo, La caja de \\ las coplas, Un zoológico en casa, \\ Lero, lero, candelero, ;Hola!, que \\ me lleva la ola y El libro de Antón \\ Pirulero. Para los lectores adultos \\ ha dado conocer Escuela y poesía \\ y Puertas a la lectura, entre otros \\ títulos. \\ Creó con Antonio Orlando Rodrí- \\ guez el sitio web especializado en \\ literatura infantil Cuatrogatos.
}

\title{
RESUMEN
}

En este artículo se realiza un acercamiento a algunas de las figuras más importantes que abrieron el camino de la creación de imágenes en las publicaciones literarias en el ámbito de Latinoamérica para los más jóvenes lectores. Con la finalidad de dar orden a nuestro material, se ha seguido un criterio cronológico en la presentación, atendiendo al momento en que estos creadores incursionaron por primera vez en la gráfica de las publicaciones para niños, ya fuera en revistas o en libros.

Palabras clave: ilustración, imagen plástica, revistas juveniles e infantiles.

\section{ABSTRACT}

In this article, a biographic approach is carried out of the most relevant authors who pioneered the design and use of illustrations in literary publications for young readers in Latin America. In order to organize our topic, the text follows a chronological order, particularly, since the very first moment when the authors published a graphic illustration in a young reader's publication, either magazines or books.

Keywords: illustration, image, youth magazine and children's magazine.

La ilustración de libros destinados a la infancia y juventud tiene una larga trayectoria en América Latina: sus orígenes se remontan al siglo xix. Aunque la plétora de autores en esta materia hace que no podamos incluirlos a todos, no obstante, aquellos que estudiamos a lo largo de estas páginas tienen un sólido aval para ser considerados no solo pioneros, sino también clásicos, por su aporte a la ilustración latinoamericana. Estos artistas realizaron contribuciones significativas al arte de la ilustración en sus respectivos países, pero asimismo se convirtieron en referentes para un gran número de creadores de la región. Todos influyeron, con la calidad de su trabajo, para que la imagen plástica cobrara mayor importancia en los libros y las publicaciones destinadas a los niños y dejara de ser un simple ornamento o repetición de lo ya expresado en el texto.

\section{Mario Silva Ossa: el mago Coré}

Un clásico indiscutible de la ilustración latinoamericana es Mario Silva Ossa, más conocido como Coré. Este artista nació en Chile, el 9 de marzo de 1913. Como era un hábil dibujante, desde muy temprano empezó a colaborar en revistas estudiantiles. Inició estudios de arquitectura, pero los abandonó a los 19 años, en 1932, cuando su tía Elvira Santa Cruz Ossa, quien era directora de la popular revista infantil El Peneca y firmaba sus artículos con el seudónimo «Roxane», lo contrató como ilustrador de esa publicación.

El semanario El Peneca, publicado por la editorial Zig-Zag, ya tenía una trayectoria de 24 años cuando el joven dibujante se sumó a su equipo creativo. Sin embargo, los 20 años en que Coré trabajó allí son considerados,
Algunos clásicos de la ilustración para niños en Latinoamérica

SERGIO ANDRICAÍN 


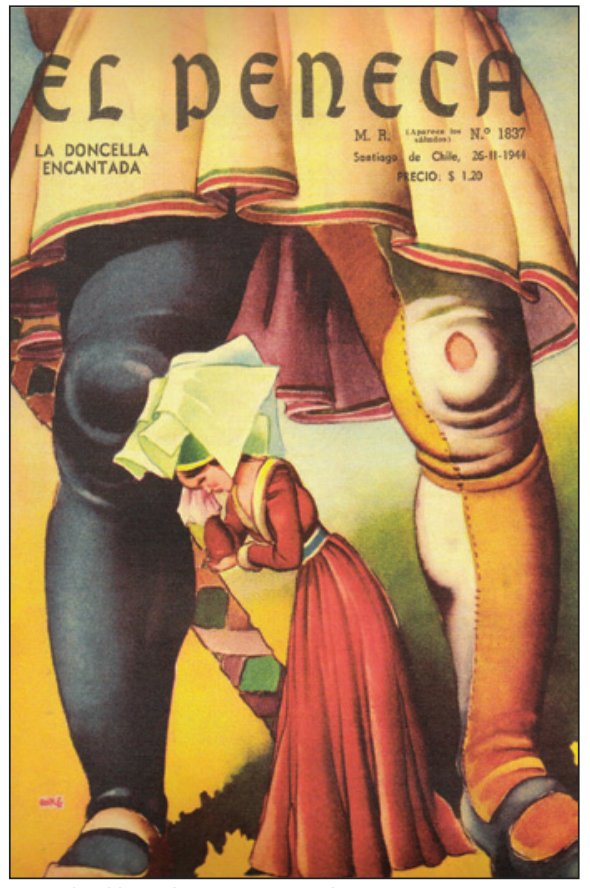

Portada dibujada por Mario Silva Ossa, Coré.

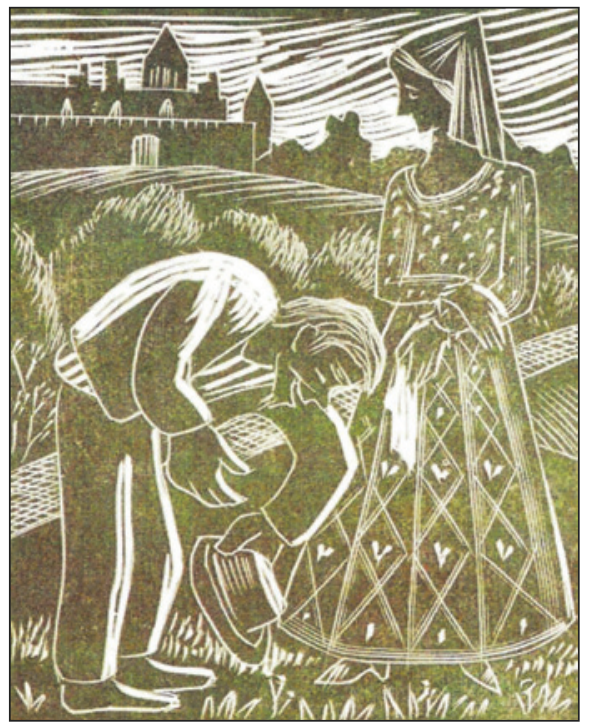

Grabado en madera realizado por Francisco "Paco» Amighetti para el cuento "El camarón encantado», de Laboulaye, en adaptación de José Martí, publicado en la revista Farolito. por la calidad de sus portadas e ilustraciones, la época dorada de la publicación. Como El Peneca llegó a circular ampliamente por América Latina, su labor logró un reconocimiento internacional.

Coré realizó decenas y decenas de portadas de El Peneca. Sus imágenes tenían un sello fantasioso, imbuido de la impronta de los artistas románticos y victorianos. En ellas se evidencia un notable dominio de técnicas como el dibujo a plumilla, la aguada y la acuarela. Para él, la expresividad facial de sus personajes - niños, hadas, duendes, princesas o reyes - era siempre objeto de particular esmero. Sus trabajos denotan un estudio minucioso del vestuario, los muebles y la arquitectura de otras épocas para dar verosimilitud a los espacios en que transcurrían las historias, a menudo medievales, renacentistas o simplemente maravillosos.

Pero la labor de Coré no se circunscribió a la revista El Peneca. Para la Biblioteca Juvenil de la Editorial Zig-Zag ilustró libros de clásicos como Emilio Salgari, Julio Verne, Oscar Wilde y Robert Louis Stevenson. También creó las imágenes visuales para obras de autores chilenos: Los conquistadores de la Antártida, de Francisco Coloane; El cazador de pumas, de Yautaro Yankas (seudónimo de Manuel Soto Morales) y Sangre y ceniza: narración novelesca de la conquista de Chile, de su tía Blanca Santa Cruz Ossa. Se estima que a lo largo de su carrera Coré hizo alrededor de diez mil dibujos.

En 1945, Silva Ossa realizó uno de sus trabajos más populares: los dibujos del muy reeditado Silabario hispanoamericano, del pedagogo chileno Adrián Dufflocq Galdames. Dos años más tarde, el escritor costarricense Joaquín Gutiérrez ganó un concurso literario convocado por la editorial de libros infantiles
Rapa-Nui con la novela corta Cocorí, un auténtico clásico de la literatura infantil y juvenil de América Latina que debería ser leído por los niños de todo el continente. Tanto la portada en colores como las ilustraciones interiores en blanco y negro de la primera edición de ese libro fueron realizadas por Coré.

Según la escritora María Silva Ossa, hermana de Coré, «su alma nunca dejó de ser la de un niño maravillado ante las cosas». En los últimos años, se han realizado exposiciones de su obra, que comienza a ser estudiada y revalorizada. Este gran artista chileno murió en 1950, poco después de cumplir 37 años de edad, atropellado por un tranvía en las calles de Santiago.

\section{Francisco «Paco» Amighetti: tras los secretos} de la madera

Entre los grandes de la ilustración para niños hay que incluir también a una importante figura de las artes plásticas de Centroamérica: el grabador, dibujante, pintor e ilustrador costarricense Francisco Amighetti, quien, además, fue cronista y poeta.

Nacido el primero de junio de 1907, Francisco Amighetti ingresó a los 19 años en la Academia de Bellas Artes de Costa Rica, pero solo estudió allí durante un curso. A fines de los años 1920 comienza a aprender la técnica de la xilografía o grabado en madera, y descubre que esa es la forma que le resulta más apropiada para expresarse artísticamente. En su formación como grabador tuvieron gran influencia los expresionistas alemanes y los grabadores mexicanos. En 1932 se vincula a los medios de prensa plana como ilustrador haciendo tanto dibujos como xilografías.

Sus primeros trabajos para niños datan de 1936, cuando ilustró dos libros de texto escolar de la pedagoga Emma Gamboa: Nuevo silabario y Lectura activa. También, en mayo de 1936, se vincula a la recién creada revista infantil mensual Triquitraque, dirigida por Carlos Luis Sáenz.

Las primeras portadas de Triquitrate fueron creadas por Amighetti, al igual que el logotipo que la identificó. También realizó la portada del primer número de la publicación. Para otras ediciones, hizo páginas de poesía que incluían poemas del español Rafael Alberti, el ecuatoriano José Carrera Andrade y la salvadoreña Claudia Lars. 
Sin embargo, a partir del número 8 (abril de 1937) sus trabajos se hacen más esporádicos. Uno de los últimos textos que ilustró para Triquitraque fue «El renacuajo paseador», poema del autor colombiano Rafael Pombo.

En 1938 Amighetti ilustra con veintiuna xilografías otro libro: Cuentos viejos, de la escritora y educadora costarricense María Leal de Noguera. Sobre este trabajo gráfico, el ensayista y editor Joaquín García Monge expresó: «Hay en las maderas de Amighetti cierta gracia y malicia muy del gusto de los niños; a más de que está presente en ellas el sentido del paisaje, del misterio y de la aventura. ¿Qué más pedir?»(Cortés). Entre las ilustraciones de este libro sobresalen las que Amighetti hizo para los textos «Otras aventuras de tío Conejo», «Historia del compadre que se sacó los ojos» $\mathrm{y}$ «Pejecito, pejesapo».

En 1941, el artista ilustra con treinta y siete xilografías la antología Poesía infantil, preparada por el poeta costarricense Fernando Luján. Su trabajo para este libro revela a un artista maduro, dueño de una técnica y una imaginación envidiables, que pone sumo cuidado en las imágenes que concibe para los niños.

En julio de 1949, Amighetti se vincula a otro importante proyecto de revista infantil. Se trata de Farolito, dirigida por la educadora Evangelina Gamboa, considerada una de las mejores publicaciones de la época en América Latina, que se publicó a lo largo de siete años, es decir, hasta 1956.

Las ilustraciones que entrega Amighetti para Farolito son de una calidad muy superior a las que había hecho para Triquitraque. Tienen su sello distintivo como grabador: una xilografía que explota al máximo las posibilidades expresivas del blanco y el negro, a los que consideraba «la quintaesencia de todos los colores»(Cortés). El artista explora las infinitas posibilidades que hay en cada veta del taco de madera para convertirlas en líneas al servicio de una idea o de un concepto a representar. «La biografía de la madera está en las vetas, y yo la uso mucho en mi grabado», solía decir ${ }^{1}$.

En Farolito, Amighetti se encarga, sobre todo, de los cuentos. Entre ellos, adaptaciones de historias de la tradición oral como «El Medio-Pollo», «Jack y la habichuela», y, en especial, el ciclo narrativo de Tío Conejo, tan importante en el folclor de Centroamérica. No faltan sus interpretaciones de clásicos como «La bella durmiente», «Blanca Nieve» o «La Cenicienta». También crea imágenes para relatos como «La niña de los fósforos», del danés Hans Christian Andersen, o «El carlanco», de Fernán Caballero, seudónimo con el que firmaba sus trabajos literarios la escritora española Cecilia Böhl de Faber.

Al observar estos y otros trabajos con detenimiento, uno descubre en ellos la emoción subyacente, la aguda intención de destacar lo que el autor expresó mediante la palabra, y de recrear para la mirada del niño intenciones coincidentes o propias. El ascendente de los grabadores expresionistas alemanes lo lleva a distorsionar

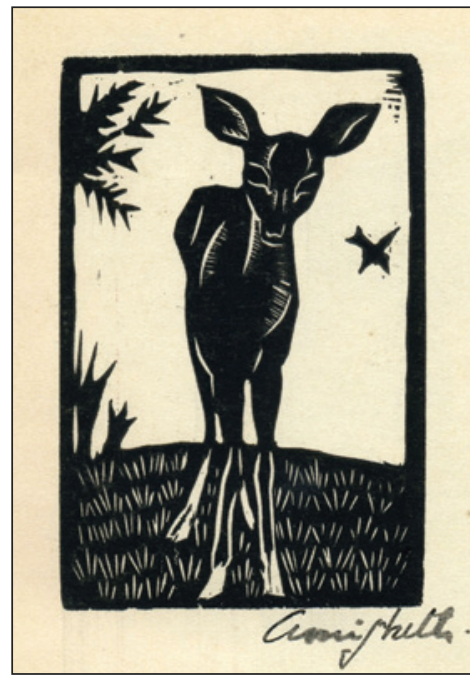

«Venadito», de Francisco «Paco» Amighetti. la realidad con el fin de resaltar ciertos detalles, de llamar la atención sobre determinado personaje u objeto. Sus sobrias ilustraciones revelan el alma de los textos a los que acompañan, su sentido más profundo, propiciando en el joven lector una experiencia estética enriquecedora. El blanco y el negro aguzan la mirada, invitan a descubrir pequeños y sutiles elementos.

Francisco Amighetti murió en 1998, a los 91 años de edad, y su nombre resulta insoslayable en cualquier recuento histórico de la ilustración para niños en América Latina.

\section{Fernando Krahn: caricaturista de buena cepa}

Otro clásico de la ilustración latinoamericana es el chileno Fernando Krahn. Nacido en Santiago de Chile, el primero de enero de 1935, desde pequeño comenzó a dibujar bajo la influencia de su padre, un abogado que, además, era un caricaturista aficionado. Según Krahn, un libro que ejerció gran influencia en él fue Max und Moritz, del ilustrador, pintor y poeta alemán Wilhelm Busch, célebre por su humor negro que hoy muchos clasificarían de «políticamente incorrecto».

Krahn dejó sus estudios de Derecho para dedicarse a diseñar escenografías teatrales. Sin embargo, su verdadera vocación se impuso cuando la revista estadounidense Esquire acogió con entusiasmo sus dibujos humorísticos. Ese fue el inicio de su ascendente carrera como caricaturista e ilustrador. En 1962 se radicó en Nueva York y comenzó a colaborar con éxito en publicaciones como The New Yorker y The Reporter.
1 Cit. por Andrés Fernández en «Cuentos viejos, maderas de Amighetti». Vid. Bibliografía final.

Algunos clásicos de la ilustración para niños en Latinoamérica

SERGIO ANDRICAÍN 
Durante un corto viaje a Chile, en 1965, conoció a la escritora María de la Luz Uribe y en menos de una semana se casaron y se fueron a vivir juntos a Nueva York. Fue entonces cuando algunas importantes editoriales estadounidenses de libros para niños se interesaron por sus dibujos, entre ellas Simon \& Schuster, Penguin y Harcourt.

Krahn inicia su trabajo editorial para niños en 1966, ilustrando, en un primer momento, libros de otros autores. Pero no tarda en realizar obras concebidas totalmente por él, como Uncle Timothy's Traviata, en 1967, y The Possible Worlds, en 1968, entre otros.

En 1969 hizo, en colaboración con María de la Luz Uribe, The First Peko-Neko

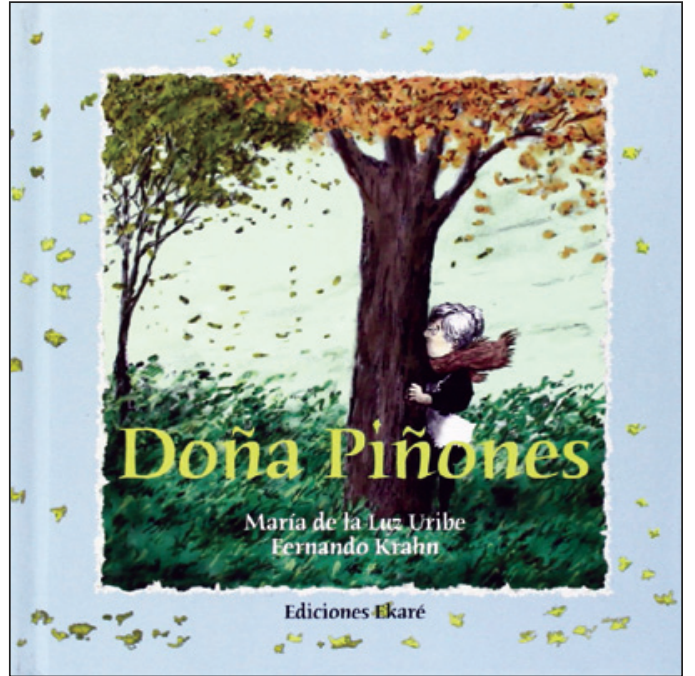

Fernando Krahn: portada para Doña Piñones.
Bird, el primero de los treinta y tres libros que crearon juntos a lo largo de su vida como pareja. Ese mismo año regresa a Chile, en compañía de su esposa e hijos, y permanece allí por varios años. Desde Santiago, sigue haciendo libros para editoriales de Estados Unidos, entre ellos Hildegarde and Maximilian y The Life of Numbers (este último con María de la Luz Uribe), publicados ambos en 1970. En 1973, en Santiago, ve la luz uno de los trabajos más populares de Krahn y Uribe: La Doña Piñones, que en la edición definitiva de Ediciones Ekaré pasará a llamarse simplemente Doña Piñones.

Cuando se produce el golpe de estado contra el presidente Salvador Allende, el artista y su familia están en Nueva York. Entonces toman la decisión de radicarse en Cataluña. Sin embargo, Krahn no descuida su producción en Estados Unidos: en 1974 aparece The Self-Made Snowman y, en 1975, Who's Seen Scissors, obras que se convierten de inmediato en dos grandes éxitos. Desde España continúa haciendo también libros en español con su esposa, como Cuenta que te cuento (1979), Cuentecillos con mote (1989), Dimes y diretes (1992) e Historia del 1 (2005), último proyecto que concibieron juntos, ya que María de la Luz falleció en 2004.
Krahn y María de la Luz recibieron, en 1982, el premio Apel-les-Mestres por La señorita Amelia y el Premio Austral 1986 por Cosas y cositas. En el año 2000, Krahn ganó el Premio Internacional de Ilustración SM por El buen amigo del cielo. En Estados Unidos, también fue galardonado en cinco ocasiones por el premio del American Institute of Graphic Arts.

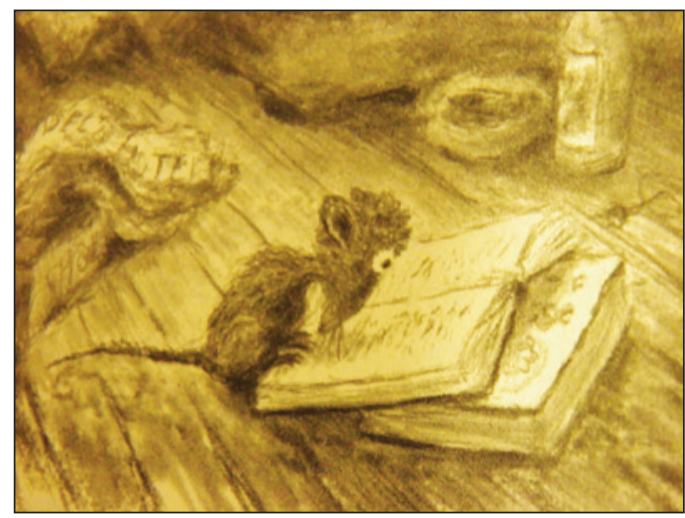

Fernando Krahn: Ilustración para Firmin, de Sam Savage.

Como caricaturista de oficio, lo más importante para Krahn era la línea, ya fuera trazada con tinta, lápiz o carboncillo. La mayoría de sus primeros libros son de dibujos a línea, en blanco y negro. Cuando usa el color, este desempeña un papel complementario, auxiliar. En Little Love Story, de 1976, lo emplea para destacar solamente un elemento de la composición. Lo mismo hace en How Santa Claus Had a Long and Difficult Journey Delivering His Present, de 1977. Sin embargo, en los años 1980 su universo comienza a llenarse de colorido, sin renunciar al personal estilo que hace reconocibles sus personajes.

El humor, refinado e incisivo, es un rasgo distintivo de su propuesta de imagen. Las ilustraciones para la edición en español de La familia Numerozzi son un buen ejemplo. Sus dibujos tienen tanta fuerza comunicativa que en ocasiones sus álbumes prescinden de las palabras para desarrollar la trama, como sucede en uno de sus libros más exitosos en Estados Unidos: Robot-bot-bot (1979). En la producción de Krahn no hay una frontera estricta que separe el estilo de dibujo que usa para los niños del que emplea para el público adulto. Su bibliografía en Estados Unidos fue numerosa tanto en libros propios como en ilustraciones para otros autores. Fernando Krahn falleció en Sitges, en el 2010.
Algunos clásicos de la ilustración para niños en Latinoamérica

SERGIO ANDRICAÍN 


\section{Eduardo Muñoz Bachs y el barroquismo tropical}

Ahora viajemos a Cuba, en los años 1960, para hablar de un artista espléndido, de gran singularidad: Eduardo Muñoz Bachs.

Muñoz Bachs nació en Valencia, España, el 12 de abril de 1937, en plena guerra civil. Sus padres eran maestros republicanos y tuvieron que exiliarse. Bachs llegó a Cuba con ellos en 1941, a los cuatro años de edad. En 1959, después de trabajar muchos años en agencias de publicidad, se vincula al recién creado Instituto de Arte e Industria Cinematográficos (ICAIC), donde destacó como diseñador de afiches para películas. Este fue su principal trabajo durante cuatro décadas. Se calcula que en total creó unos dos mil doscientos carteles de cine, la inmensa mayoría de ellos serigrafías y muchos para filmes infantiles. Estas obras gráficas lo hicieron merecedor de importantes premios en Estados Unidos y en Francia.

De forma paralela a su labor como afichista, Muñoz Bachs incursionó en el terreno del cine de animación y desarrolló una importante carrera como ilustrador de libros infantiles, que se inició en 1963, cuando realizó los dibujos de Cuentos de animales, de Herminio Almendros, pedagogo español radicado en la isla, quien dirigía la Editora Juvenil. Luego vendrían otros muchos proyectos editoriales en Cuba y en el extranjero. Por ejemplo, entre 1974 y 1975 ilustró para la editorial Gente Nueva la trilogía Cuentos para ti, una compilación de textos de varios autores cubanos.

Algunos de los trabajos inolvidables de este maravilloso artista son Abuelita Milagro, de Antonio Orlando Rodríguez, publicado en 1977; Caminito del monte, de David Chericián, en 1980; Cuentos de cuando La Habana era chiquita, de Antonio Orlando Rodríguez, en 1984; Cantos para un mayito y una paloma, de Excilia Saldaña, en 1983; Los payasos, de Dora Alonso, en 1985, y Juan Ligero y el Gallo Encantado, también de Dora Alonso, en 1999.

En la estética de este ilustrador se conjugan lo grotesco y lo lírico, lo profuso y lo mínimo. El universo visual de Bachs es caribeño por adopción, universal por su proyección. Barroco en la composición, carnavalesco en su espíritu, con tendencia al empleo de colores fuertes que se contraponen y llegan a mezclarse con delicadas transparencias. Muñoz Bachs definió un estilo personal, de marcado humorismo. No es casual que sus personajes parezcan escapados de un retablo de guiñol. En una entrevista que le dio a su hijo Fabián Muñoz dijo que «el libro infantil es como un teatro de títeres» (Muñoz).

En su etapa final, ilustró para varias editoriales extranjeras. Por ejemplo, en 1989 hizo El circo en la ciudad, de Bruno Horst Bull, en Alemania; en 1991, Dailan Kifki, de María Elena Walsh, en Suecia; en 1999, Consejos del abuelo Conejo, de Jorge Timossi, en Japón, y en 1993, Balada de los dos abuelos, de Nicolás Guillén, en Francia.

Eduardo Muñoz Bachs murió en La Habana, en 2001. Era un hombre de pocas palabras, que prefería hablar a través de sus dibujos. "Soy del criterio de que toda ilustración que se haga, bien sea para las páginas de un libro o para las de una revista, para un cartel o para la carátula de un disco, o hasta para la señalización de un hospital infantil, debe contribuir a que el niño se familiarice con todos los

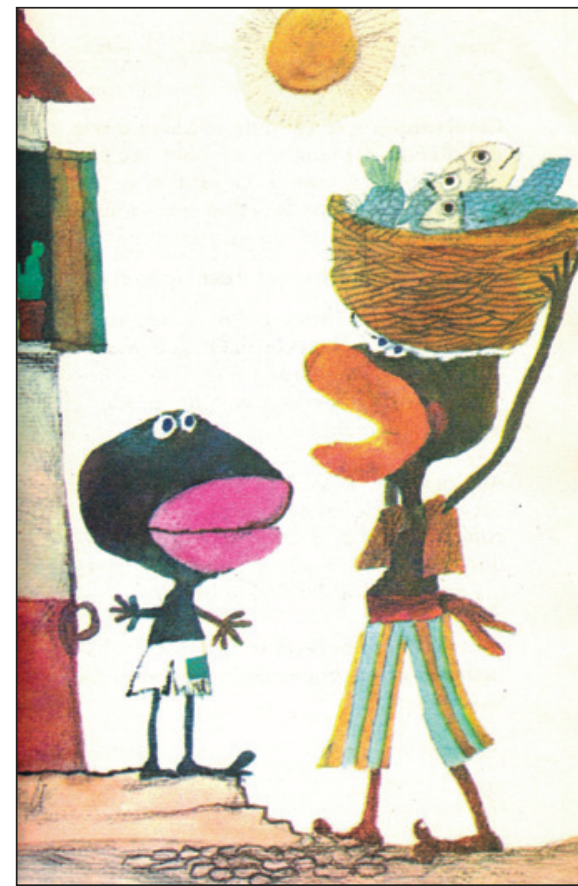

Eduardo Muñoz Bachs ilustró Cuentos de cuando La Habana era chiquita. lenguajes de las artes plásticas», me dijo en una de las contadas entrevistas que concedió (Andricaín 68-85).

\section{Ayax Barnes, un maestro de la línea}

Durante la década de 1960, en Argentina se produce un movimiento renovador en la ilustración infantil que rompe con la tradición asociada a la gráfica de revistas como Billiken y Anteojito. Por ejemplo,
Algunos clásicos de la ilustración para niños en Latinoamérica

SERGIO ANDRICAÍN 


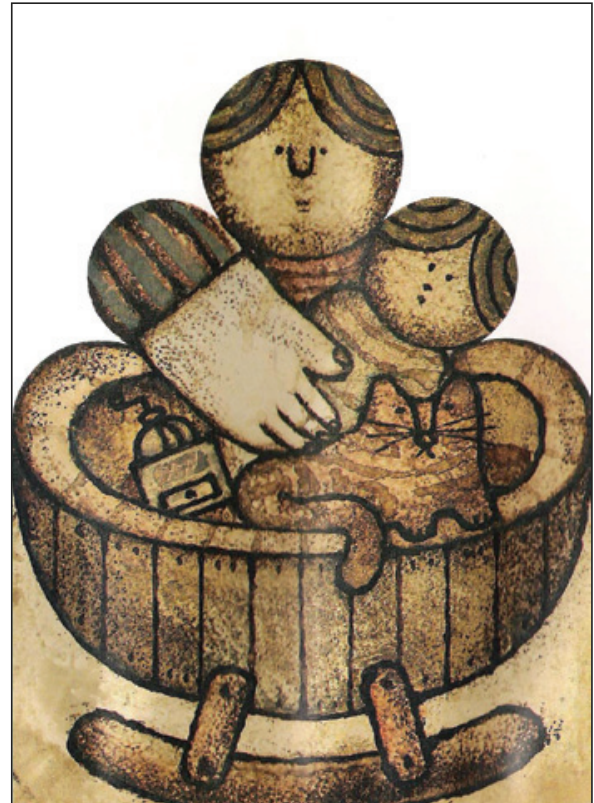

Aserrín aserrán. en Córdoba, en 1966, Víctor Viano ilustra el primer libro de Laura Devetach: La torre de cubos. Por su atrevido uso del fucsia y el naranja, y por su figuración y composición, se trata de una propuesta original que sintoniza con una de las tendencias punteras de la época: el pop art.

A mediados de los 1960, en Buenos Aires, surge la colección infantil Cuentos de Polidoro, publicada por el Centro Editor de América Latina. En esta serie participaron ilustradores con visiones atrevidas y refrescantes. Entre ellos, Hermenegildo Sábat, Napoleón, Oscar Grillo y Ayax Barnes. Nos detendremos en este último por su larga y reconocida trayectoria, que lo convierte en uno de los grandes de la gráfica para niños de América Latina.

Ayax Barnes nació en Rosario, Argentina, en 1926. Inició su carrera de diseñador e ilustrador en Montevideo. Con su esposa, la escritora Beatriz Doumerc,

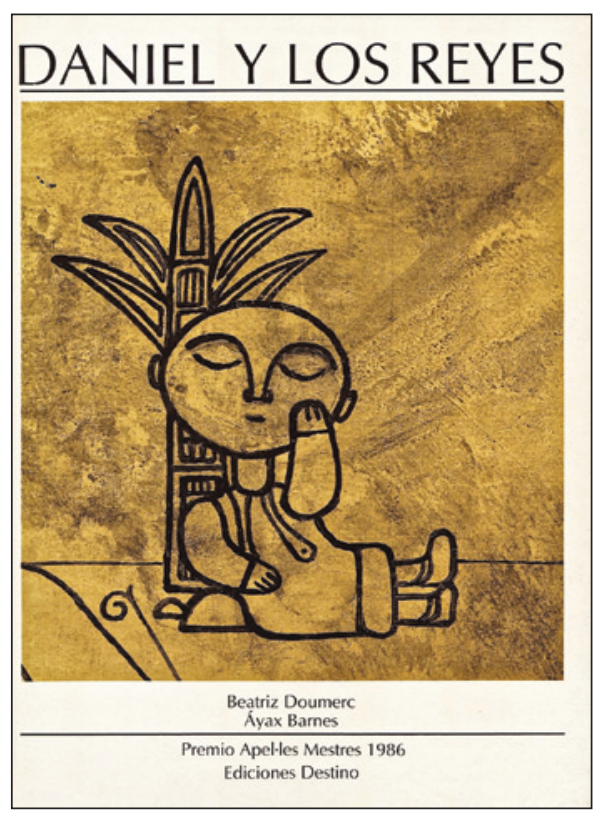

Ayax Barnes: portada de Daniel y los reyes. integró una fructífera dupla creativa que dio a conocer un buen número de obras significativas.

En Buenos Aires, Barnes colabora con colecciones como Cuentos de Polidoro y Los Cuentos de Chiribitil. En esos proyectos, Barnes entregó trabajos antológicos; por ejemplo, Las aventuras de Ulises, de Cuentos de Polidoro, que se continúa reeditando en el presente. En 1975, Beatriz Doumerc y Ayax Barnes ganaron el premio Casa de las Américas, de Cuba, con su obra La línea. La publicación de este álbum, de un contenido social acorde con el espíritu combativo de los años 1970, fue uno de los motivos que llevó a la pareja a escapar de Argentina en 1977, tras recibir amenazas de una organización paramilitar. Este libro, de una simplicidad paradigmática, hoy admite una lectura de ca- en sí mismo, una exaltación de las posibilidades expresivas y comunicativas de la línea.

Poco antes del golpe militar, Barnes y Doumerc habían dado a conocer también otro libro que fue considerado non grato y prohibido por las autoridades de la dictadura militar: El pueblo que no quería ser gris, una metáfora política de la situación de Argentina en aquella época. Los dibujos de esta obra, hechos con brea, trasmiten la atmósfera hostil y represiva de esos difíciles tiempos.

En el exilio, Barnes y Doumerc vivieron, primero, en Italia, donde publicaron una de sus obras más conocidas: Cuando todo pasa volando. Posteriormente se radicaron en España, en la ciudad de Barcelona. Allí prosiguieron su labor creativa y se ganaron un merecido prestigio en el ámbito editorial de ese país.

En 1984 dan a conocer uno de sus libros de mayor encanto: Aserrín aserrán (que fue publicado en Suecia por iniciativa de un colectivo de exiliados suramericanos). En Aserrín aserrán, Barnes recurre a un único formato - utilizado como un cliché-, a una misma gama de colores ocres y tierra y a una gruesa línea negra; a partir de ese pie forzado hace gala de su imaginación y de su maestría para componer. En 1986, el binomio Doumerc-Barnes ganó en España el premio de álbum ilustrado Apel-les-Mestres con un cuento de inspiración bíblica: Daniel y los reyes.

Barnes trabajó muchas técnicas, desde el grabado y el dibujo a línea hasta el collage, sin olvidar los papeles recortados de $E l p a ́$ jaro Federico. Este notable artista murió en Barcelona, en 1993, dejando tras de sí un mundo sumamente personal, capaz de conectar con lectores de cualquier edad. En sus ilustraciones no hay nada superfluo, trabaja con lo esencial, buscando la comunicación sin elementos distractores.

\section{Ângela Lago y sus sempinternas mutaciones}

Hay grandes figuras de la ilustración que a lo largo de su trayectoria se mantienen, en lo esencial, fieles a un estilo, a una manera de hacer. Sin embargo, otros creadores conciben su labor artística como una cadena de búsquedas, hallazgos, rupturas y nuevas indagaciones. La obra de la brasileña Ângela Lago - quien nació en Belo Horizonte, Minas Gerais, en 1945 - se inserta en la segunda de esas categorías y puede ser interpretada, en 
su conjunto, como resultado de un perenne cuestionamiento sobre la naturaleza y el sentido de la ilustración.

A partir de 1982, con la publicación de Uni duni e tê, Lago define una forma de expresión propia, caracterizada por la insistencia en el detalle y el virtuosismo del dibujo a línea. Estos hallazgos se prolongan y perfeccionan en libros posteriores como Outra vez (1984) y Chiquita Bacana e as outras pequetitas (1986). En estos dos libros, el color adquiere especial relevancia, así como la obtención, con acuarelas y lápices, de una textura aterciopelada que invita a ser acariciada, a detener la mirada sobre cada detalle del dibujo.

Esta etapa de Ângela Lago alcanza su culminación en $O$ cântico dos cânticos (1992), un relato con una doble narrativa visual de inspiración islámica, con atrevidas perspectivas que evocan al holandés M. C. Escher. Este álbum laberíntico lo dibujó a lo largo de seis años y puede leerse comenzando por la primera de sus páginas o por la última, y poniendo sus páginas hacia arriba o hacia abajo.

Pero, mientras cerraba una etapa, daba inicio a otra, atraída por las posibilidades de la computación y las tecnologías digitales. Lago sorprende en 1990 con el libro Sua Alteza a Divinha, concebido, como se indica en la cubierta, "con la amable colaboración de ilustradores anónimos y antiguos». Dos años después, llega De morte!, otro cuento del folclor brasileño, ilustrado esta vez «con una leve manita de Alberto Durero», como señala, con un toque de humor, la ilustradora en la cubierta del libro. En este díptico se alcanza una admirable conjunción texto-diagramación, que permite que gráfica y palabra, más que dialogar, se integren festiva e imaginativamente. Hechos en computadora, estos libros son la antípoda del preciosista $O$ cântico dos cânticos, en tanto que se comunican con los lectores a través de un lenguaje directo, sintético e irónico.

Cena de rua (1994) marca otro cambio de dirección en su estilo, tanto por su contenido - una mirada a la dura realidad de los niños de la calle- como por su filiación expresionista, evidente en el empleo del color y en el dramatismo de la figuración. En 1996, Pedacinho de Pessoa usa como detonante líneas de versos del poeta portugués Fernando Pessoa, para volver sobre el expresionismo, pero con otros matices e intenciones, tal como sucede también en Indo não sei aonde buscar não sei o quê (2000).

En el año 2011 Ângela Lago ilustró la edición brasileña de la colección de $L i$ mericks Zooloco, de la escritora argentina María Elena Walsh, esta vez combinando y manipulando dibujos y fotografías en la computadora, con un desenfado mayúsculo. Múltiple y única, Ângela Lago convierte cada libro en una sorpresa y en una rica experiencia estética.

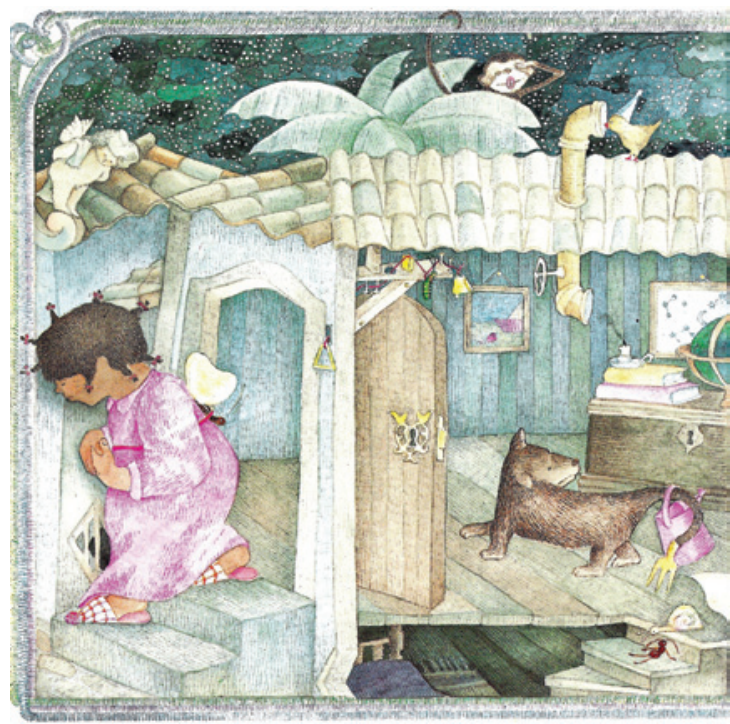

Dibujo de Ângela Lago para su libro de imágenes Outra vez.

\section{Alekos: el folclor como fuente}

Otro tanto puede afirmarse del artista colombiano Alexis Forero, «Alekos», nacido en Bogotá en 1950, y radicado en Barcelona. Por su colorido, su sentido de la composición y su espíritu festivo, su quehacer está estrechamente asociado con las expresiones del arte popular latinoamericano.

Alekos ha explorado un sinfín de posibilidades dentro de la ilustración para niños. Desde la imitación del grabado en madera (como en las ilustraciones para el cuento «Concierto para escalera y orquesta», de Antonio Orlando Rodríguez, publicado en la revista infantil Espantapájaros a principios de la década de 1990) hasta fotografías intervenidas con técnica mixta (propuesta que desarrolló en Espantajos, un libro de su autoría, en el 2003).

A lo largo de su trayectoria, Alekos

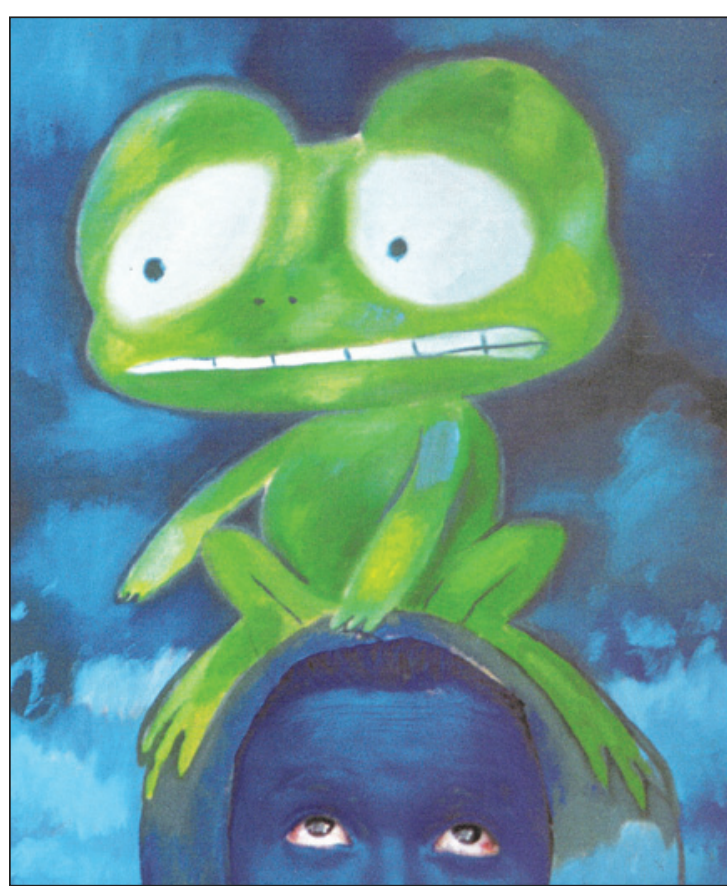

Espantajos, escrito e ilustrado por el artista colombiano Alekos (Alexis Forero). ha logrado algo difícil: hacer gala de una inagotable capacidad de renovación, pero sin renunciar nunca a ser él mismo. Algunos
Algunos clásicos de la ilustración para niños en Latinoamérica

SERGIO ANDRICAÍN 
trabajos suyos de especial significación son la edición venezolana de Mi bicicleta es un hada y otros secretos por el estilo, de Antonio Orlando Rodríguez, publicada por Ediciones Rondalera; los Cuentos, de León Tolstoi, publicados por Panamericana Editorial en Colombia, y Pastorcita, un cuento en verso de Rafael Pombo, editado como libro álbum en la colección Nidos de lectura de Alfaguara, Colombia.

\section{Coda}

Para terminar, se impone mencionar a otros maestros latinoamericanos de la ilustración que han realizado aportes de mérito en libros y publicaciones periódicas para niños y jóvenes. Entre ellos, Pedro Vilar y Oscar Rojas, de Argentina; Jorge Rigol, Andrés García Benítez, Reinaldo Alfonso y Enrique Martínez, de Cuba; Morella Fuenmayor, de Venezuela; José Manuel Sánchez y Vicky Ramos, de Costa Rica; Carlos Pellicer López, Gabriel Pacheco y Fabricio Vanden Broeck, de México; Gian Calvi, de Brasil; Ivar Da Coll, Esperanza Vallejo y Olga Cuéllar, de Colombia.

Con estos apuntes he intentado transmitir la riqueza de la ilustración para niños en América Latina y la diversidad de técnicas y vertientes artísticas que han explorado los artistas gráficos de la región para educar la mirada estética de los lectores a lo largo de las últimas nueve décadas. Si estos apuntes despiertan el deseo de continuar investigando sobre el tema, me sentiré muy complacido.

\section{Bibliografía sugerida}

Aguilera, Claudio. Antología visual del libro ilustrado en Chile (Fotografías: Alfredo Méndez). Valparaíso, Chile: Quilombo Ediciones, 2014.

Andricaín, Sergio. «En torno a la ilustración infantil cubana: un diálogo abierto». En julio como en enero, 10 (1992): 68-85.

Cortés, Carlos. "Amighetti a los 79 años. Francisco y los caminos». www.franciscoamighetti.com/entrevistas/entrevista1. htm (sitio oficial del artista).
Fernández, Andrés. "Cuentos viejos, maderas de Amighetti». http://andferblog. blogspot.com.es/2011/08/cuentos-viejosmaderas-de-amighetti.html. Consulta 19 de agosto de 2011.

Montealegre, Jorge. Coré. El tesoro que creíamos perdido. Santiago, Chile: Ediciones Asterión, Colección La Castaña, 2012.

Muñoz, Fabián. «Muñoz Bachs: El libro ilustrado es como un teatro de títeres». Prográfica, 16 (2001). http://www.prografica. cult.cu/boletines/Mensajes16.htm

Paz-Castillo, María Fernanda (ed.). Cuadernos de Literatura infantil y juvenil: Una historia del libro ilustrado para niños en Colombia. Bogotá, Colombia: Biblioteca Nacional de Colombia, 2010.

Ossa, María Silva. Perejil Piedra. Santiago, Chile: Quilombo, 2015.

\section{Consultas en internet:}

Diccionario de Ilustradores Iberoamericanos SM:

http://www.smdiccionarioilustradores. com/index_i.php

Sitio oficial de Francisco Amighetti: www. franciscoamighetti

Sistema Nacional de Bibliotecas, Costa Rica, Colección revista Triquitraque en línea: http://www.sinabi.go.cr/biblioteca $\% 20$ digital/revistas/Triquitraque.aspx\#.VcgswEVhrsY

Sistema Nacional de Bibliotecas, Costa Rica, Colección revista Farolito en línea: http:// www.sinabi.go.cr/biblioteca\% 20digital/ revistas/Farolito.aspx\#.VcgtAOVhrsY

Artistas Plásticos Chilenos (APCh), Biblioteca y Centro de Documentación del Museo Nacional de Bellas Artes de Chile en línea: www.artistaschlenos.cl/

Imaginaria. Ayax Barnes. Informe preparado por Marcela Carranza: http://www.imaginaria.com.ar/2010/11/ayax-barnes/

Sitio oficial de Ângela Lago: http://www. angela-lago.net.br/

Sitio oficial de Alekos: http://www.alekos.info/

Fecha de recepción: 5/05/2015

Fecha de aceptación: 1/10/2015 